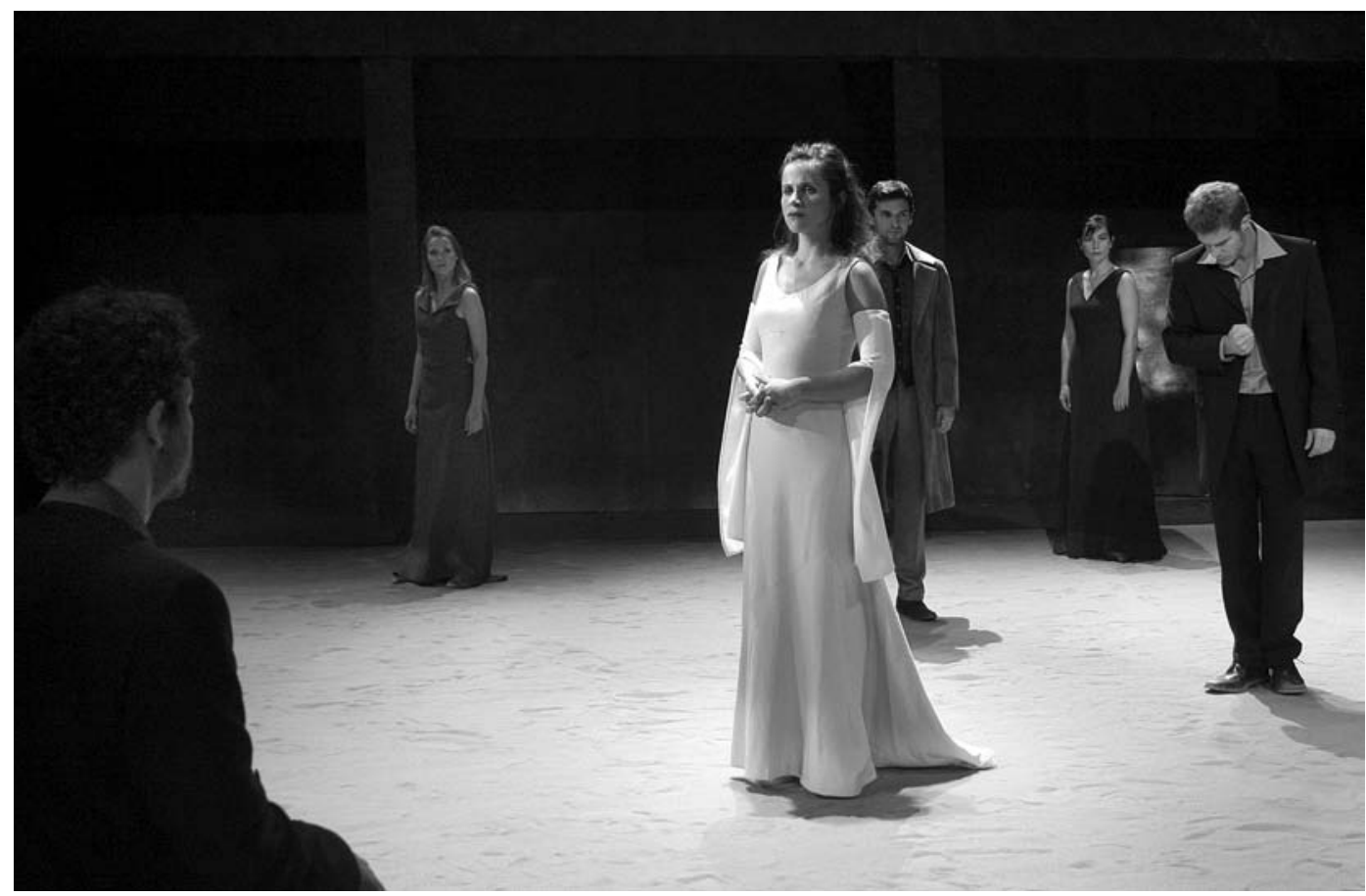

\title{
Fricções entre dramaturgia e cenografia
}

\author{
Jean-Pierre Han
}

Ao ler e reler a temática do seminário, dou-me conta de que, ao fim e ao cabo, me convidam a fazer um ponto da situação sobre o teatro de hoje no meu país, a França. A fazer, de certo modo, um retrato dessa matéria eminentemente viva e... difícil de fixar, que é o teatro. Com efeito, e para ir rapidamente ao assunto, a questão principal que agita nos dias de hoje o nosso teatro é, sem dúvida, a seguinte: uma fricção (perdoem-me a utilização deste termo que, apenas por uma letra, é o da ficção de que se trata no título da temática, mas é também o título da revista que criei!) entre dramaturgia e cenografia. $\mathrm{Ou}$, se se quiser traduzir, entre o texto e a imagem. A dramaturgia tem em França um sentido duplo. 0 sentido, cada vez mais em desuso, de designar a arte da composição dos textos e o sentido que diz respeito às "condições da passagem à cena de um texto de teatro". A cenografia, por seu lado, designa, segundo Guy-Claude François (1991: 753-754), cenógrafo de Ariane Mnouchkine entre outros, "a arte de dar forma ao espaço da representação". Dar forma material, portanto, visual.

Vendo bem, foi este confronto que esteve artificialmente em evidência na edição de 2005 do Festival de Avinhão que tanta tinta fez correr em França. É ainda dessa fricção que se trata no teatro de hoje. Ora, como por acaso, se quisermos tentar fazer um balanço do que se passa nos nossos palcos na hora actual, dar-nos-emos conta de que se revelam dois eixos principais que correspondem, por um lado, à predominância da dramaturgia (do texto e da sua passagem ao palco), que nos remete para uma certa tradição ou um certo classicismo; ou da cenografia, que nos remete para uma certa modernidade.
É este duplo aspecto que me proponho evocar na minha intervenção.

Mas ainda antes de entrar verdadeiramente no centro da problemática gostaria de continuar a evocar o título do seminário. Desta vez, foi o próprio termo "ficções" que me interpelou com insistência. A ficção remete para aquilo que é da ordem do imaginário e logo perante outra problemática muito forte que agita o nosso pequeno universo do teatro há mais de quinze anos: a da questão do real, do teatro do real, do teatro documentário. Chegado aqui, tenho de dizer uma palavra sobre a realidade política e social da época (os anos 90). Um dos slogans do nosso Presidente da República de então, Jacques Chirac, era "reduzir a fractura social". De repente "descobria-se" que existia um fosso entre várias fracções da população, que existiam nomeadamente "zonas" problemáticas que se tinham tornado perfeitamente ingovernáveis, verdadeiras zonas de "não direito". 0 que Chirac se propunha fazer era nada menos do que acabar com este estado das coisas (hoje podemos ver os resultados!). Na mesma época, aparecia nas livrarias um enorme calhamaço, La misère du monde, do sociólogo Pierre Bourdieu, que reunia uma série de entrevistas que ele próprio e a sua equipa tinham realizado junto duma população confrontada com graves problemas na vida quotidiana. 0 livro teve um enorme sucesso, particularmente junto da gente de teatro que se agarrou a todos os textos para os pôr em cena, apesar das reticências de Pierre Bourdieu que teve o cuidado de explicar que esses textos não tinham nada de teatral, que, de qualquer modo, não tinham sido escritos para serem levados à cena! É que, ao grito de alerta de Jacques Chirac, o mundo teatral sentiu-se obrigado a acompanhar (ou a
Jean-Pierre Han é presidente da Associação Francesa da crítica dramática e musical (Syndicat français de la critique dramatique et musicale) e dirige a revista trimestral Frictions: Théâtres Écritures. 


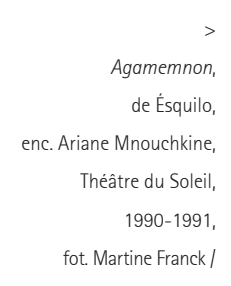

Magnum.

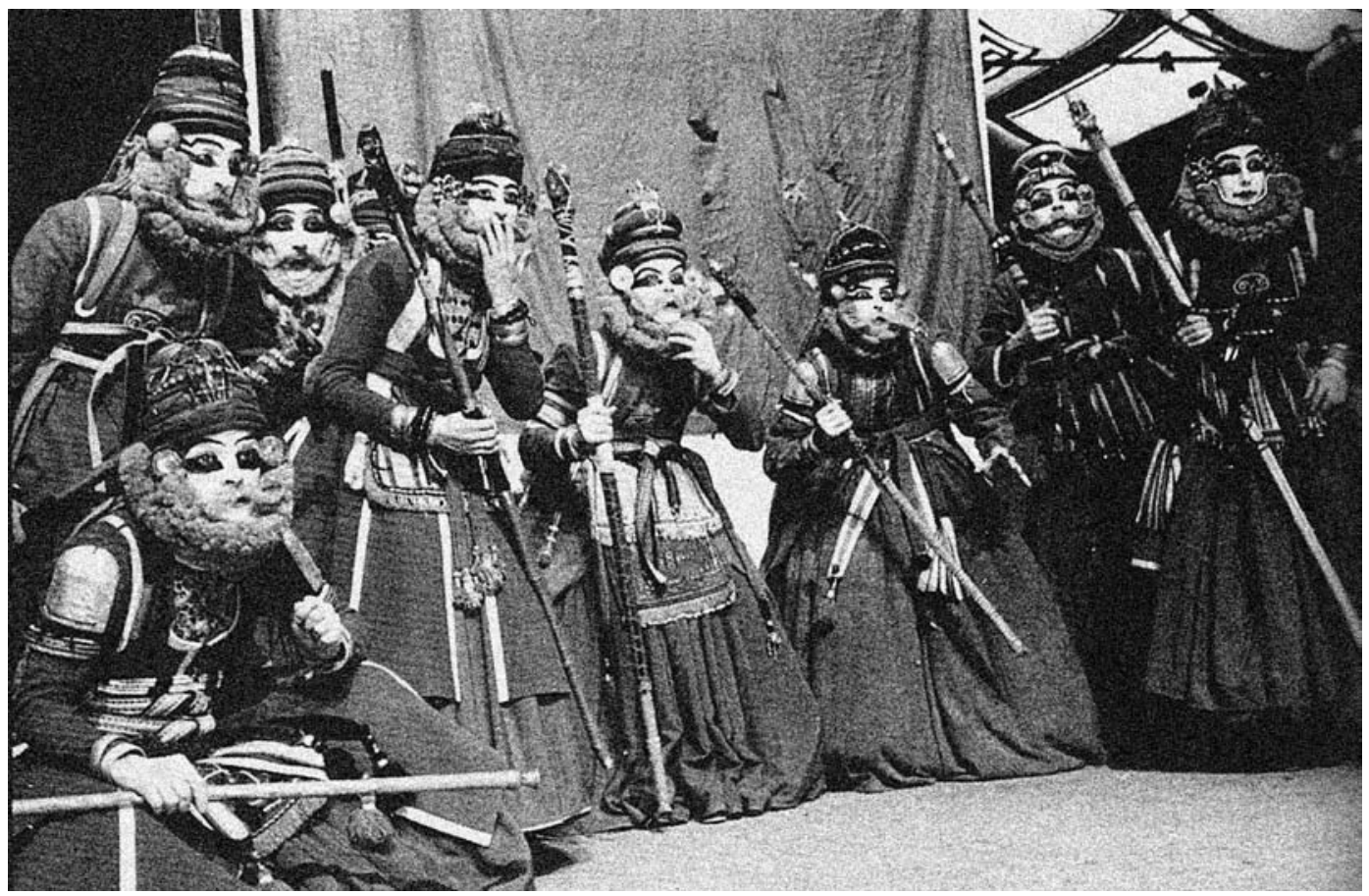

provocar, varia conforme os observadores) o movimento, quer dizer, sentiu-se também obrigado a dedicar-se à tarefa de "reduzir a fractura social". A questão que se colocava então ao teatro era a da sua necessidade, da sua utilidade. Para que serve o teatro? Interroga-se então um teórico como Denis Guénoun, seguido por um grande número de colegas seus. (Aquele título tornou-se, aliás, recorrente.) 0 teatro é necessário? Responde-Ihe JeanLoup Rivière que dirige na altura os Cahiers de la Comédie Française. Duas facções se opõem com violência: uma que defende o carácter gratuito do teatro, em suma, a arte pela arte, outra que defende que o teatro se deve comprometer com as lutas sociais e apresentar espectáculos evocando esses problemas. A questão chega a assumir contornos caricatos: põem-se no palco jovens dos subúrbios em espectáculos escritos à pressa que evocam a vida desses subúrbios. É ai que o livro de Pierre Bourdieu tem um êxito estrondoso; todas as entrevistas - que têm pelo menos o mérito de terem sido reescritas - são representadas à saciedade. E então, no que respeita à ficção, ao imaginário... Em suma, só o real era imaginário! Contento-me aqui em evocar rapidamente este episódio que teve, pelo menos, o mérito de levantar grandes questões, nomeadamente as do realismo, do teatro político, etc., problemas que estão longe de estarem resolvidos.

Chego agora (finalmente!) ao cerne da questão.

Ao querer a todo o custo fazer um ponto da situação da criação teatral contemporânea, pedido que actualmente me é dirigido com alguma regularidade, suponho que devido à minha idade avançada na profissão de espectador profissional, e uma vez esgotados os argumentos, pareceme que efectivamente se podem identificar dois eixos. Dois eixos antagónicos, dum antagonismo velho como o mundo (do teatro), que põem em oposição clássicos e modernos. Oposição que, fique bem claro, não tem nada de geracional. A tradição, relativamente moderna, quer que $o$ acto teatral seja realizado segundo o esquema autor - encenador - actores, numa espécie de hierarquia imutável. É esta hierarquia que certos artistas vêm pondo em questão há algum tempo. Uma das variantes desse questionamento passa pelo facto de essas três funções poderem ser assumidas por uma única e mesma pessoa, o que, ao fim e ao cabo, não é senão um regresso às próprias origens do teatro! Em todo o caso, na primeira categoria encontramos um grande número (a maioria) de artistas, e a esse propósito temos de evocar aqui o problema da formação. Ou da não-formação, visto que em França, ao contrário de outros países, não houve, durante muito tempo, por exemplo, formação em encenação, devendo cada um desenvencilhar-se como podia graças à autoproclamação ou, no melhor dos casos, a uma aprendizagem no terreno que passava nomeadamente pela assistência de encenação, etc. Não é de espantar que alguns encenadores da nova geração se considerem órfãos, termo utilizado por Frédéric Maragnani. Esta situação alterouse recentemente, mas não tenho aqui espaço para evocar a qualidade e a pertinência das novas formações, o que, de resto, é outro problema.

Resumindo, temos por um lado jovens encenadores que perpetuam um teatro que, mesmo tendo integrado todos os elementos da modernidade, continua a ser clássico ou tradicional na sua concepção. Veja-se, por exemplo, e uma vez que estamos em Portugal, um jovem encenador como Emmanuel Demarcy-Mota, que possui um perfeito domínio da sua arte claramente clássica, quer trabalhe com textos clássicos como os de Shakespeare quer com textos perfeitamente contemporâneos como os de Fabrice Malquiot, com quem colabora regularmente. A propósito desta nova geração de encenadores (e talvez isso tenha alguma influência sobre a sua maneira de praticar o teatro de forma tradicional), sublinharei também o facto de um grande número deles vir da universidade onde muitas vezes fizeram estudos brilhantes (é o caso de Irène Bonnaud ou de David Lescot, por exemplo).

Por outro lado, apareceram artistas que tentam pôr em causa a maneira de praticar a sua arte. São muito sensiveis às outras artes: coreográfica, do circo, da rua, da marioneta, etc. Muitas vezes servem-se do texto apenas 

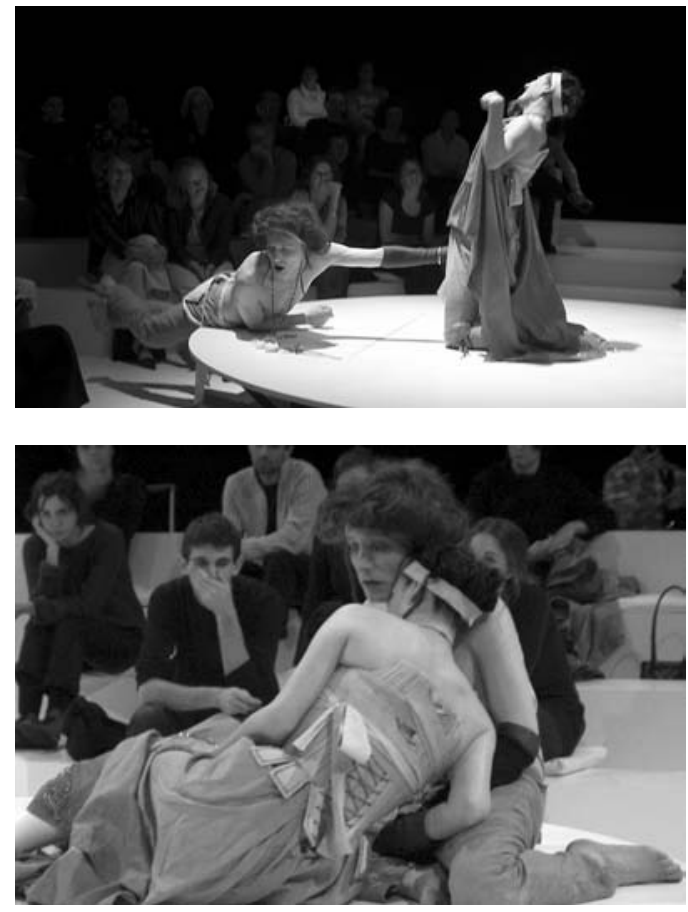

como material (e nesse estádio todos os textos, não forçosamente teatrais, são utilizados), são influenciados pelas performances e pelo seu lado "improvisado". As tecnologias modernas, como o vídeo, as imagens de síntese, são regularmente utilizadas, infelizmente nem sempre de forma criteriosa. Há que notar aqui a influência crescente das artes plásticas, e uma reflexão apoiada e constante sobre os espaços de representação. Os cenógrafos têm hoje em dia um papel determinante na concepção dos espectáculos. Talvez seja uma consequência da contribuição dos encenadores que têm hoje ente quarenta e cinquenta anos - estão, a bem dizer, todos à frente das grandes instituições teatrais do pais - e que, à falta de melhor, optaram por uma formação em Belas-Artes. Penso em Robert Cantarella, Dominique Pitoiset, Éric Vigner... Em alguém como Stéphane Braunschweig, director do Teatro Nacional de Estrasburgo (o TNS) que realiza e assina todas as suas cenografias. Por seu lado, um cenógrafo importante como Daniel Jeanneteau, que trabalhou muito com Claude Régy, virou-se para a encenação. No seu Théâtre postdramatique, Hans-Thies Lehmann já tinha identificado esta propensão do teatro para lidar com a transversalidade; aqui estamos em pleno na transversalidade. 0 título deste seminário teria sido impensável ainda há poucos anos.

Que esta problemática seja assim enunciada já diz muito.

Se a imaginação (a das "ficções") está no poder, gostaria de sublinhar o facto de todos os artistas que se podem associar aos dois eixos que evoquei terem em comum a teimosa vontade de falar, de uma maneira ou de outra, de forma directa ou indirecta, da realidade (fantasmada ou não) do mundo. Eis um verdadeiro ponto de "convergência". Ao caos do mundo, à sua violência, corresponderia o caos do palco. Não é francamente por acaso que Heiner Müller continua a exercer uma grande influência sobre as jovens gerações de encenadores que não param, como Célie Pauthe, Irène Bonnaud, Benoît Gasnier, e mais alguns, de andar à volta da sua obra. E faço questão em sublinhar aqui a influência em França de um homem de teatro, autor, encenador, director de companhia, prematuramente desaparecido aos 40 anos nos anos 90, Didier-Georges Gabily. Do seu grupo (o grupo $T^{\prime} C h a n ' G$ ) saiu um grande número de encenadores que contam nos dias de hoje: Jean-François Sivadier, Serge Tranvouez, Yann-Joël Collin, Christian Esnay... Também ele se propunha falar do mundo de hoje, da sua violência, das suas guerras; ele tinha tentado e conseguido casar mitos antigos e mitos modernos, o intimo e o universal.

\section{Referências bibliográficas}

BOURDIEU, Pierre (1993), La misère du monde, Paris, Seuil.

FRANÇOIS, Guy-Claude et al. (1991), "Scénographie: esthétique", in Dictionnaire Encyclopédique du théâtre, Dir. Michel Corvin, Paris, Bordas.

LEHMAN, Hans-Thies (2002), Le héâtre postdramatique, Paris, L'Arche.

Tradução de Luís Varela
$<$

Quartett,

de Heiner Müller, enc. Célie Pauthe, TNT - Théâtre de la Cité a Toulouse, 2003 (Pierre Baux e Violaine Schwartz), fot. Sebastien Michaud. 